\title{
IMPACTO DO ESTUDO START - O INÍCIO DE UMA NOVA ERA NO TRATAMENTO DO HIV
}

\author{
IMPACT OF START TRIAL - THE BEGINNING OF A NEW ERA IN HIV \\ TREATMENT
}

Bruno Araújo Jardim; Maurício De Carvalho; Mônica Maria Gomes Da Silva1

\begin{abstract}
RESUMO
Até recentemente, existia grande debate sobre o melhor momento para se iniciar terapia antirretroviral (TARV) em pacientes com infecção por HIV. Evidências apontavam para o início de TARV somente para pacientes com contagem de CD4+ menor que 500 células $/ \mathrm{mm}^{3}$. O estudo START, um ensaio clínico randomizado multicêntrico publicado em agosto de 2015 , buscou responder quais os aspectos positivos e os negativos do início precoce de TARV (início do tratamento em pacientes com contagem de CD4+ maior que 500 células $/ \mathrm{mm}^{3}$ ) em relação ao seu início tardio (contagem de CD4+ menor ou igual a 350 células $/ \mathrm{mm}^{3}$ ), em pacientes adultos com HIV. Este ensaio clínico mostrou benefícios do início precoce de TARV quanto a eventos sérios relacionados ou não à AIDS em comparação ao grupo com início tardio de TARV, sem evidência de aumento estatisticamente significativo de efeitos adversos no primeiro grupo. Os resultados do estudo levaram a Organização Mundial da Saúde a recomendar início de TARV para todos os adultos com infecção por HIV, fato que deve acarretar uma grande mobilização para que se alcance o objetivo do tratamento global dos pacientes com HIV.
\end{abstract}

\section{ABSTRACT}

Until recently, there was much debate about the best time to start antiretroviral therapy (ART) in patients with HIV infection. Evidences pointed to the start of ART only for patients with CD4+ count less than $500 \mathrm{cells} / \mathrm{mm}^{3}$. The START trial, a multicenter randomized clinical trial published in August 2015, sought to answer what the pros and cons of early initiation of ART (initiation of therapy in patients with $\mathrm{CD}+$ count greater than 500 cells $/ \mathrm{mm}^{3}$ ) in relation to its late start (CD4+ count less than or equal to $350 \mathrm{cells} / \mathrm{mm}^{3}$ ) in adult patients with HIV. This clinical trial showed benefits of early initiation of ART as the serious events related or not to AIDS compared to the group with late initiation of ART, with no evidence of a statistically significant increase in adverse effects in the first group. The study results led the World Health Organization to recommend early ART for all adults with HIV infection, a fact that should cause a great mobilization for achieving the goal of comprehensive treatment of patients with HIV.

1 - Universidade Federal do Paraná (UFPR), Curitiba, Brasil

Contato do autor/mail to:

Bruno Araújo Jardim - brunojardim89@hotmail.com

Rua General Carneiro, 181 - Alto da Glória - Curitiba - PR 
O melhor momento para o início da terapia antirretroviral (TARV) em paciente com infeccção por HIV foi assunto de debate por vários anos. Avaliar os benefícios reais da terapia precoce em comparação aos potenciais riscos da toxicidade medicamentosa oferecida por terapias sustentadas durante toda a vida do paciente foi o objetivo de diversos estudos e debates entre especialistas na área.

Sabe-se que a perda das células CD4+ na infecção por HIV está diretamente relacionada à imunodeficiência associada à AIDS, levando às complicações e ao óbito consequentes da doença. Classicamente, o início do tratamento da infecção por HIV sempre se baseou na contagem de células CD4+, um dos principais alvos do HIV no corpo humano, havendo evidências com maior ou menor robustez de se iniciar tratamento em pacientes assintomáticos, a depender do ponto de corte da contagem de CD4+ utilizado pelos estudos. Um ensaio clínico avaliou uma estratégia de uso de TARV guiada por CD4+, a fim de tentar reduzir o tempo de uso contínuo de antirretrovirais. Neste estudo, os pacientes infectados pelo HIV foram randomizados em dois grupos: um grupo com estratégia tradicional, com TARV contínua, e outro grupo com terapia baseada na contagem de CD4+, cujo início se deu em um ponto de corte de de 250 células $/ \mathrm{mm}^{3}$, posteriormente submetendo-se à suspensão do tratamento na vigência de carga viral indetectável e contagem de CD4+ a partir de 350 células $/ \mathrm{mm}^{3}$, com posterior reinício do tratamento quando houvesse novamente uma contagem de CD4+ de 250 células $/ \mathrm{mm}^{3}$. Este ensaio clínico, denominado SMART, foi interrompido precocemente pois concluiu-se que suspender a TARV foi prejudicial aos pacientes, estando isto relacionado a desfechos negativos (maior risco de óbito por qualquer causa e de doenças oportunistas $)^{1}$.
Após este periodo, o uso de TARV esteve relacionado à menor ocorrencia de transmissão de HIV entre humanos. Esta estratégia, denominada treatment as prevention, guiou algumas diretrizes, como a brasileira, que recomendam o início de antirretrovirais mais precocemente ${ }^{2}$. Entretanto, a evidência de benefício para a saúde individual no início precoce de TARV, definindo-se "precoce" como início da terapia na contagem de CD4+ acima de 500 células $/ \mathrm{mm}^{3}$, não existia até recentemente. 0 estudo intitulado Strategic Timing of Antiretroviral Therapy (START) ${ }^{3}$ buscou responder quais os aspectos positivos e os negativos da estratégia de início precoce de TARV em pacientes com contagem de CD4+ maior que 500 células $/ \mathrm{mm}^{3}$, em comparação à TARV tardia, em pacientes com contagem de CD4+ menor ou igual a 350 células $/ \mathrm{mm}^{3}$.

Os critérios de inclusão para o estudo START foram os seguintes: 1) infecção por HIV, 2) idade maior ou igual a 18 anos, 3) ausência de TARV prévia, 4) ausência de história de AIDS, 5) bom estado de saúde geral e 6) CD4+ maior que 500 células $/ \mathrm{mm}^{3}$. Gestantes e lactantes foram excluídas do estudo, com exceção das mulheres que gestaram no decorrer do ensaio clínico. O estudo foi randomizado, dando origem a dois braços (Figura 1): um grupo com início imediato de TARV (grupo intervenção) e um com início tardio de TARV (grupo controle). 0 grupo com TARV tardia teve indicação de início de tratamento quando respeitasse qualquer uma das seguintes condições: contagem de $\mathrm{CD} 4+$ de 350 células $/ \mathrm{mm}^{3}$, desenvolvimento de evento relacionado à AIDS ou outra condição que indicasse TARV, como gestação por exemplo. 0 estudo foi iniciado em 2009 e respeitou as diretrizes de tratamento de infecção por HIV da época, seguindo as recomendações do Department of Health and Human Services.

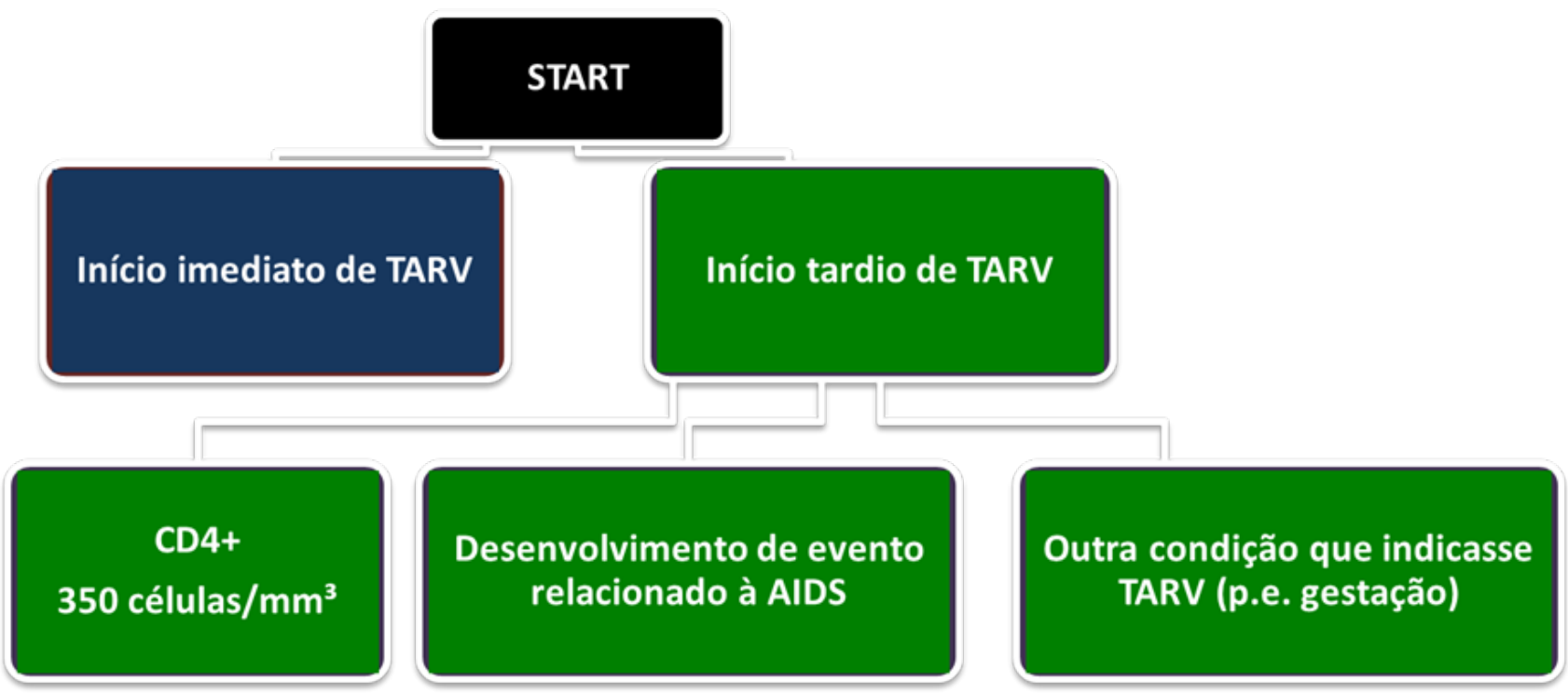

Figura 1. Randomização dos grupos e indicações de tratamento no grupo com início tardio de TARV 
Os pesquisadores participantes receberam cegamento, e revisores independentes analisaram os resultados do estudo, o qual foi interrompido em 15 de maio de 2015, por ter sido respondido o seu questionamento primário. Em 27 de maio do mesmo ano, pesquisadores e pacientes foram então informados sobre os achados do ensaio clínico.

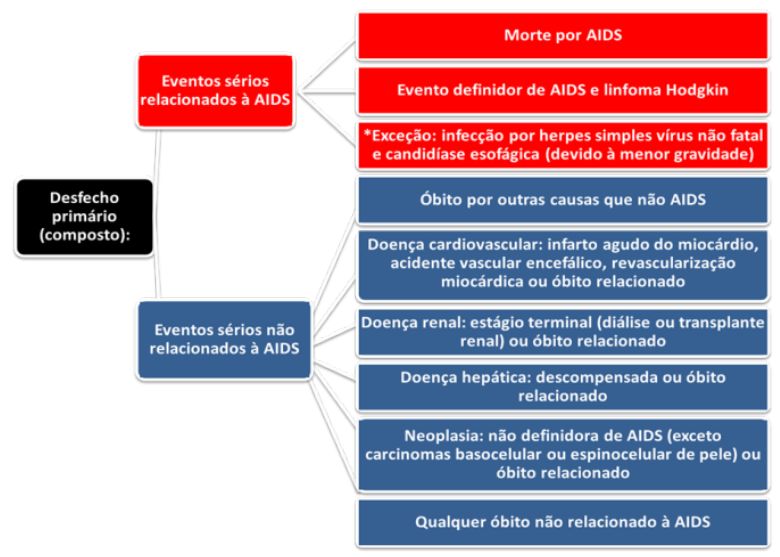

Figura 2. Desfechos primários do estudo START

Um total de 4.685 pacientes foram recrutados entre abril de 2009 e dezembro de 2013 em 215 centros de 35 países, sendo então acompanhados. 0 fim do seguimento de cada indivíduo se deu no dia 26 de maio de 2015 ou na data do último contato com os pesquisadores durante o ensaio clínico. A análise estatística do estudo envolveu intenção de tratar (isto é, todos os pacientes recrutados foram incluídos na análise do grupo ao qual foram randomizados), curvas de sobrevida de KaplanMeier e modelos de Cox, e o hazard ratio e os intervalos de confiança de $95 \%$ foram elaborados a partir de estimativa por modelo de Cox estratificado de acordo com 6 regiões geográficas - África; Europa e Israel; América do Norte; América do Sul e México; Austrália e Ásia. Foram realizadas análises de sensibilidade (para avaliar os efeitos da certeza diagnóstica dos eventos e dos dados ausentes) e de subgrupos, categorizados de acordo com 8 características: idade, sexo, grupo racial, região geográfica, contagem de $\mathrm{CD} 4+$ basal, contagem de carga viral basal, tabagismo e estratificação de risco cardiovascular em 10 anos.

Houve apenas uma pequena parcela de pacientes com desfecho primário desconhecido: $4 \%$ no grupo intervenção e $5 \%$ no grupo controle. Os pacientes foram seguidos por uma média de 3 anos, com mediana de 2,8 anos, havendo um total de $23 \%$ dos indivíduos que foram acompanhados por mais de 4 anos. 0 braço do estudo que recebeu TARV imediata apresentou menor hazard ratio comparado ao grupo com TARV tardia: 0,43 $(0,30-0,62 ; p<0,001)$ para o desfecho primário composto, com redução de risco relativo (RRR) de $56 \%$, redução de risco absoluto (RRA) de 2,3\% e número necessário para tratar (NNT) de 44. Também obteve menor hazard ratio na avaliação de eventos sérios relacionados à AIDS - 0,28 $(0,15-0,50 ; p<0,001)$, com RRR de $72 \%$, RRA de 1,5\% e NNT de 66 - e eventos sérios não relacionados à AIDS $0,61(0,38-0,97 ; p=0,04)$, com RRR de 37\%, RRA de $0,74 \%$ e NNT de 134. O grupo intervenção também foi superior quanto a desfechos secundários no que diz respeito a infecções bacterianas e a um desfecho composto por eventos grau 4, hospitalização não eletiva ou desfecho primário. Além do mais, não houve aumento de efeitos adversos no grupo com TARV imediata. A análise de subgrupos confirmou os achados a favor do grupo com início imediato de TARV. A seguir, curvas de Kaplan-Meier ilustram alguns dos principais achados do estudo (Figuras $4,5$ e 6$)$.

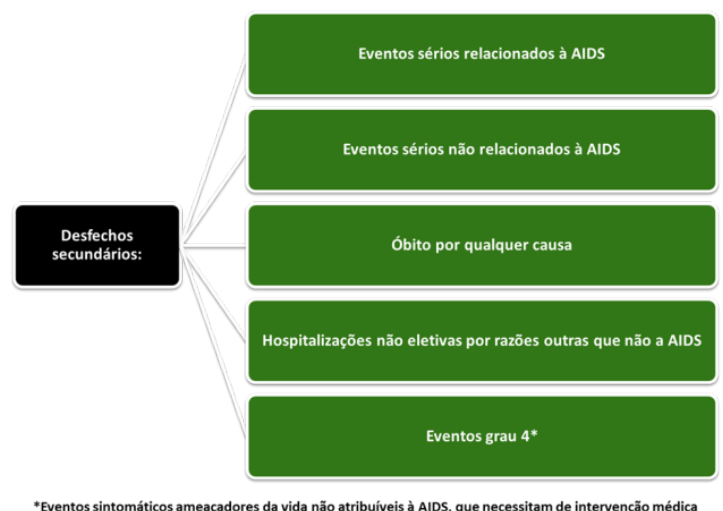

Figura 3. Desfechos secundários do estudo START

O estudo TEMPRANO, um ensaio clínico randomizado multicêntrico realizado em pacientes da Costa do Marfim e publicado concomitantemente ao START, teve conclusões semelhantes a este quanto ao benefício do início precoce de TARV em pacientes com infecção por HIV3. As conclusões destes estudos levaram a Organização Mundial de Saúde a recomendar o início precoce de TARV a todos os pacientes adultos (acima de 19 anos) com HIV, com qualquer contagem de CD4+, em suas mais recentes diretrizes4. Todavia, considerando-se que a estimativa de pessoas no mundo vivendo com HIV em 2014 foi de 36,9 milhões, com apenas 15 milhões recebendo TARV, temos o outro lado da questão: qual o custo do tratamento global destes pacientes e como alcançar o objetivo da terapia precoce? Principalmente no que tange o combate ao HIV nos países mais pobres, certamente será necessária uma mobilização global para que se possam concretizar as novas recomendações de tratamento na infecção por HIV5. 


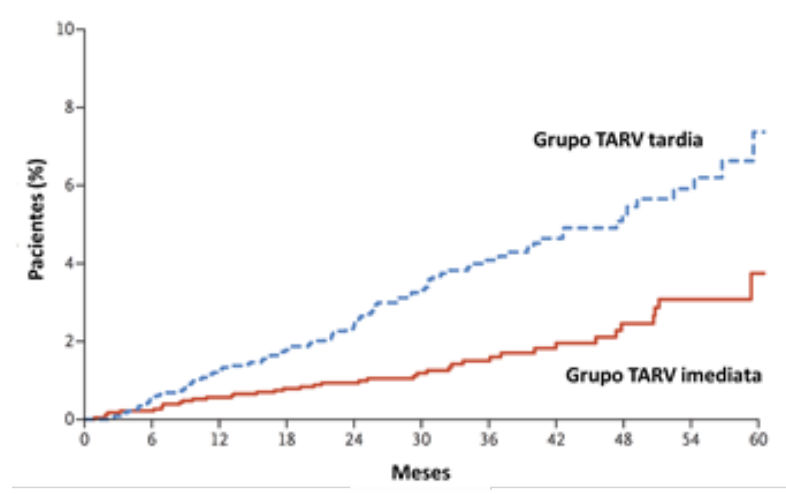

Figura 4. Tempo até o primeiro evento do desfecho primário. Modificado de Lundgren et al, 2015.

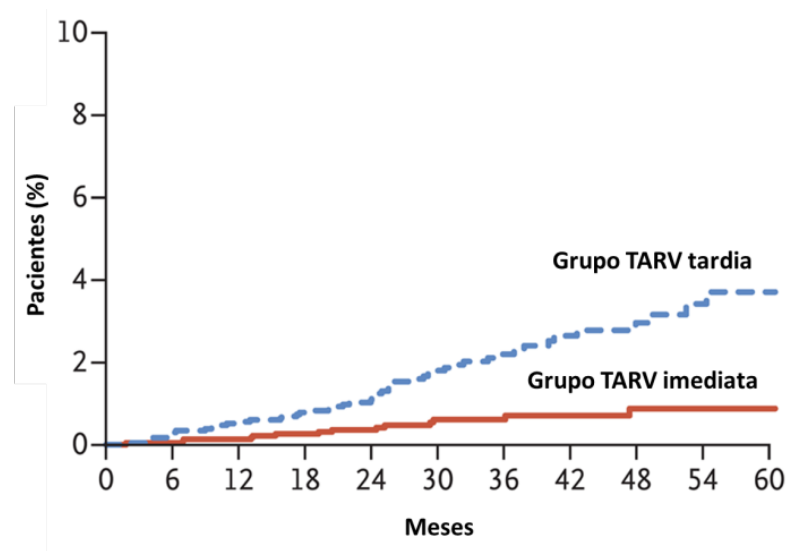

Figura 5. Eventos sérios relacionados à AIDS. Modificado de Lundgren et al, 2015.

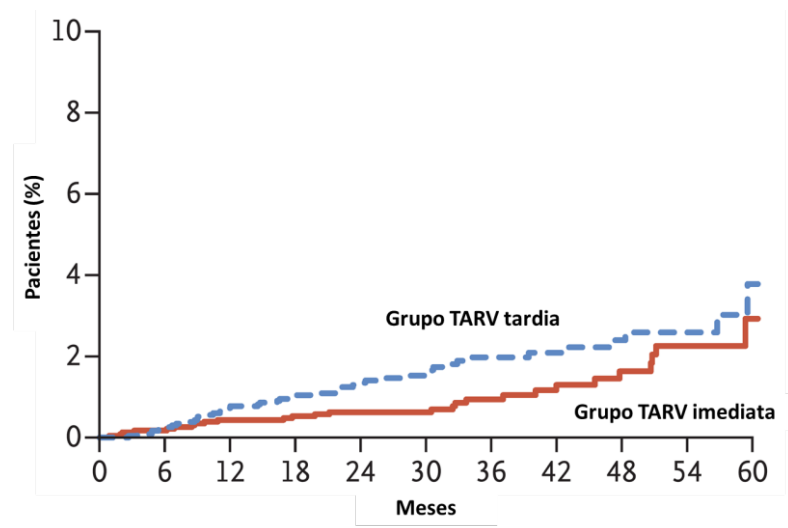

Figura 6. Eventos sérios não relacionados à AIDS. Modificado de Lundgren et al, 2015.

\section{Referências}

1. LUNDGREN, J. D. et al. CD4+ Count-Guided Interruption of Antiretroviral Treatment. New England Journal of Medicine, Copenhague, v. 355, n. 2, p.2283-2296, 30 nov. 2006. Disponível em: < http://www.nejm.org/doi/pdf/10.1056/NEJMoa0623 60>. Acesso em: 30 ago. 2015.
2. BRASIL. MINISTÉRIO DA SAÚDE. Protocolo clínico e diretrizes terapêuticas para manejo de infecção pelo HIV em adultos. 2013. Disponivel em: <http://www.aids.gov.br/sites/default/files/anexos/p ublicacao/2013/55308/protocolo_final_31_7_2015_ pdf_30707.pdf>. Acesso em: 30 ago. 2015.

3. LUNDGREN, J. D. et al. Initiation of antiretroviral therapy in early asymptomatic HIV infection. New England Journal of Medicine, Copenhague, v. 373, n. 9, p.795-807, 27 ago. 2015. Disponível em: <http://www.nejm.org/doi/pdf/10.1056/NEJMoa150 6816>. Acesso em: 30 ago. 2015.

4. AKA, K. et al. A trial of early antiretrovirals and isoniazid preventive therapy in africa. New England Journal Of Medicine, Bordeaux, v. 373, n. 9, p.808822, 27 ago. 2015. Disponivel em: <http://www.nejm.org/doi/pdf/10.1056/NEJMoa150 7198>. Acesso em: 30 ago. 2015.

5. ORGANIZAÇÃO MUNDIAL DA SAÚDE (Suíça). Guideline on when to start antiretroviral therapy and on preexposure prophylaxis for HIV. 2015. Disponivel em: <http://apps.who.int/iris/bitstream/10665/186275/ 1/9789241509565_eng.pdf?ua=1>. Acesso em: 05 out. 2015.

6. KARIM, S. S. A. Overcoming impediments to global implementation of early antiretroviral therapy. New England Journal Of Medicine, Durban, v. 373, n. 9, p.875-876, 27 ago. 2015. Disponível em: <http://www.nejm.org/doi/pdf/10.1056/NEJMe1508 527>. Acesso em: 30 ago. 2015. 